\title{
The Impact of Blackboard LMS on Teaching Research Method Course for Technology Studies Graduate Students at the Arabian Gulf University
}

\author{
Alajab Mohammed Alajab Ismail and Ahamed Ali Salih
}

\begin{abstract}
A learning management system (LMS) is a software application or web-based technology used to plan, develop, implement, and assess a specific learning process. In Open and Distance Learning (ODL), learning management systems are used to provide tutors with ways to create and deliver e-content, monitor students` participation as well as assess their performance. Learning management systems like WebCT \& Blackboard were used at the Arabian Gulf University since the academic year 2003/2004 for course delivery and learners` engagement. The Blackboard Learning Managements System (LMS) represents one of the powerful academic solutions that provide true learning activities management, deep interactions with the course material facilitate learner engagement and lead to higher level of satisfaction with learning The present study is mainly intended to explore how Blackboard (LMS) integrated and used for improving the outcomes of a blended learning-based research methods course taught at the Arabian Gulf University for around 43 master candidates affiliated to AGU technological graduate studies programs during the academic years 2010/2011 (control group) and 2011/2012 (experimental group). Analysis of data obtained revealed that using Blackboard as a learning management system facilitated research methods candidates learning, enhanced their learning outcomes as well as their satisfaction with the learning experience.
\end{abstract}

Index Terms-Blackboard LMS, distance education, learning outcomes, research methods, technological studies programs, and satisfaction with learning.

\section{INTRODUCTION}

Blackboard Learning Management System (LMS) works with thousands of institutions worldwide to help them with their educational challenges and help them drive innovation in education. The first blackboard system was the HEARSAY-II speech understanding system [1] that evolved between 1971 and 1976. While the basic features of Hearsay-II remain in today's blackboard systems, numerous advances and enhancements have been made as a result of experience gained in using blackboard systems in widely varying application areas. Before using any technology for learning purposes it is better to train your students on how to make use of such a technology. In [2] authors investigated the effective

Manuscript received March 8, 2017; revised May 23, 2017. This work was funded by the Arabian Gulf University, College of Graduate Studies.

Alajab Mohammed Alajab is with the Department of Distance Learning, College of Graduate Studies, Arabian Gulf University, Manama, B.O.Box:26671 Kingdom of Bahrain (e-mail: alagabm@agu.edu.bh).

Ahmed Ali Salih is with the Desert and Aridzone Program, College of Graduate Studies- Arabian Gulf University. Manama, B.O.Box:26671, Kingdom of Bahrain (e-mail: ahmedalis@agu.agu.edu.bh). utilization of Information and Communication Technology (ICT) by firs-year undergraduates of the University of Botswana (UB) in their reading and writing skills. The first year students are not first language (L1) learners of English. They have not utilized computers for learning reading and writing in their basic education and have not been exposed to such Learning Management Systems (LMS) as Blackboard and Moodle at the secondary school level. Consequently, at the university, when they are required to utilize computers in reading and writing in their core courses, this becomes a huge challenge. They investigated how UB first year undergraduates utilize the computer as an ICT tool in their reading and writing skills using the quantitative and qualitative research methods. A questionnaire was administered to 200 students enrolled in both ICT 121 and ENG 131 courses during the second semester of 2013/2014 academic year. In addition, interviews and classroom observations over the same period were conducted by the researchers. The constructivist theory of learning formed the theoretical framework. The findings revealed that most first year students have difficulty in downloading and uploading course materials using the LMS platforms; they are also unaware of the silent interactive communication offered by the computer as an ICT tool. The researchers recommend that first year undergraduate students should be given lots of practice on the use of the LMSs and computer skills for effective performance in their academic work.

Authors [3] conducted a study to answer the research questions on the accessibility and usability of the blackboard vista e-learning software and the barriers of user experience when interacting with the blackboard LMS at King Saud University. The study was based on the hypothesis that Blackboard LMS is highly accessible and usable by teachers in the King Saud University and a hypothesis that stated otherwise. The elements that were evaluated using questionnaires included the design user interface, navigational features, and ease of use to answer the research questions. The results accepted the hypothesis that 'Blackboard LMS is accessible and usable by the teachers from different faculties for the delivery of content in the King Saud University. However, the study recommends that the university should customize the e-learning software to the needs of the teachers to offer courses in English and in Arabic to increase and enhance the accessibility and usability of the software.

Blackboard LMS is in wide use by Saudi higher education institutions and colleges, and many studies were conducted to assess the effectiveness of Blackboard usage in higher 
education outcomes. For example, Hussein [4] investigated the effect of Blackboard-based instruction on pre-service teachers' achievement in the teaching methods course at the Faculty of Education for Girls, in Bisha, KSA. Forty seventh-level English Department students were randomly assigned into either the experimental group $(\mathrm{N}=20)$ or the control group $(\mathrm{N}=20)$. While studying their teaching methods course, the experimental group received instruction via Blackboard Collaborate, whereas the control group received traditional instruction. The two groups were pre-post tested using a teaching methods test prepared by the course instructor. Two hypotheses were formulated and tested. Results obtained from Wilcoxon Signed Ranks Test and Mann-Whitney Test revealed that the Blackboard-based instruction was effective in enhancing the achievement of the experimental group. In addition, compared to traditional instruction, Blackboard-based instruction was more effective in improving the participants' achievement as it provided them with multiple opportunities to explore alternative means to interact with teachers, peers, course material, and activities. Yu-Je[5], discussed the relationship between instructional innovation, learning satisfaction, and student achievement in technological and vocational colleges (TVC) in Taiwan.The results showed that: 1) teaching innovation has a significant and positive influence on learning satisfaction; 2) teaching innovation also has a significant positive influence on students' study achievement; 3) learning satisfaction and study achievement were interrelated, with a positive correlation existing between them. Yi- Ju, and Po-Chung [6] examined perceptions of levels of Satisfaction and Learning occurs in an online program as relates to Salmon's Five Step Teaching and Learning Model [7] of Interaction (Access and Motivation, Online Socialization, Information Exchange, Knowledge Construction, and Development). The study results showed that providing good Access and Motivation are critical for influencing Satisfaction levels. Similarly, if one wants to influence Learning levels, Information Exchange and the Developmental use of information are necessary for beginning online users.

Hong [8] discussed the results of a study about the effect of students' and instructional variables on satisfaction and achievement in a Web-based course. Results indicated that gender, age, learning styles, time spent on the course, and perceptions of student-student interactions, course activities, and asynchronous Web-based conferences were not related to satisfaction and learning outcomes. Moreover, he found that those students who entered the course with better Cumulative Grade Point Average (CGPA) scores achieved higher final grades in the course, but did not express more satisfaction with the learning environment. Computer experience did not influence achievement but experienced computer users were more satisfied with the course. Students who perceived the student-instructor interactions positively felt that their discussion group had performed well during the conferences, and viewed the learning materials used in the conferences positively improved grades and were more satisfied with the course. Students expected instructor-led learning.

Johnson and his colleagues [9] compared a graduate online course with an equivalent course taught in a traditional face-to-face format on a variety of outcome measures. Their comparisons included student ratings of instructor and course quality; assessment of course interaction, structure, and support; and learning outcome measures such as course grades and student self-assessment of their ability to perform various Instructional Systems Design (ISD) tasks. Results revealed that the students in the face-to-face course held slightly more positive perceptions about the instructor and overall course quality although there was no difference between the two course formats in several measures of learning outcomes.

\section{A. LMS and Higher Education Students Achievement}

Because student engagement is believed to be a predictor of academic achievement, there is significant interest in discovering methods that can improve and increase student engagement at all levels of education. In [10], authors investigated the relationship between digital and social media usage and student engagement. In particular, their study sought to investigate how adding (1) a learning management system (LMS) and (2) a dedicated marketing Twitter feed influenced the self-reported engagement levels of undergraduate marketing students. The results showed that students were more engaged when the LMS and Twitter feed were used. Specifically, Twitter usage had a positive impact on engagement with a marketing course while LMS usage had a positive impact on engagement with the School of Business. Seniors significantly used the LMS more than underclassmen but there were no differences in Twitter usage between these groups. The results also showed that students were most engaged with their marketing course, followed by the College, and the School of Business respectively.

Two of the most important outcomes of learning analytics are predicting students' learning and providing effective feedback. Learning Management Systems (LMS) like Blackboard, which are widely used to support online and face-to-face learning, provide extensive research opportunities with detailed records of background data regarding users' behaviors. Firat [11] investigated the effects of undergraduate students' LMS learning behaviors on their academic achievements. In line with this purpose, the participating students' online learning behaviors in LMS were examined by using learning analytics for 14 weeks, and the relationship between students' behaviors and their academic achievements was analyzed, followed by an analysis of their views about the influence of LMS on their academic achievement. A total of 71 undergraduate students participated in the study. The results revealed that the students used LMSs as a support to face-to-face education more intensively on course days (at the beginning of the related lessons and at nights on course days) and that they activated the content elements the most. Lastly, almost all the students agreed that LMSs helped increase their academic achievement only when LMSs included such features as effectiveness, interaction, reinforcement, attractive design, social media support, and accessibility.

Learning Management Systems (LMS) are being integrated into the curriculum by many educational institutions to extend teaching and learning beyond the classroom. In [12] Lata and Luhach, conducted a case study exploring the integration of LMS Nalanda created on Moodle in Effective Public 
Speaking (EPS) classroom to give students an additional platform to practice, collaborate and discuss speech writing. Out of many teaching and learning facilities available on LMS, the researcher chose online forum as a tool for giving additional practice in speech writing. This tool helped in enhancing the learner centeredness on one hand and encouraged equal participation of all the group members on the other. The present paper looks at the researcher's observation of the outcomes of the integration process. One of the important findings was that students' interaction on online forums resulted in improvement of students' performance in speech writing. Higher participation, constructive feedback, and community of practice resulted in enhancement in their speech organizing abilities while preparing the speech draft. Vygotsky's socio-cultural theory which holds the active, interactive and collaborative role of learners in the entire learning process has been used as its theoretical basis.

The blended learning environment in university courses integrates teaching technologies in traditional (i.e. non-technological) learning contexts, most evidently through the adoption of a Learning Management System (LMS). Lai and Savage [13] highlighted areas in which LMS supports and/or hinders "good" teaching and learning. Instructors' and students' perceptions of LMS around these seven principles were examined through in-depth interviews and focus groups, consisting of fieldwork conducted with seven leading instructors and three groups of undergraduate students. They broadly represent all faculties at McMaster University. Preliminary findings suggest that LMSs are particularly useful administratively but are perceived by students and instructors as a poor substitute for classroom teaching. Results further suggest students were most engaged in the learning process when instructors communicated their interests and passion in teaching through classroom environments that were then reflected in the on-line components of a university course.

Earlier studies have suggested that higher education institutions could connect the predictive power of Learning Management System (LMS) data to develop reporting tools that identify at-risk students and allow for more timely pedagogical interventions. Macfadyen and Dawson [14] provided data from an international research project investigating which student online activities accurately predict academic achievement. Analysis of LMS tracking data from a Blackboard Vista-supported course identified 15 variables demonstrating a significant simple correlation with student final grade. Regression modelling generated a best-fit predictive model for this course which incorporates key variables such as "total number of discussion messages posted", "total number of mail messages sent", and "total number of assessments completed" and which explains more than $30 \%$ of the variation in student final grade. Logistic modelling demonstrated the predictive power of this model, which correctly identified $81 \%$ of students who achieved a failing grade. Moreover, network analysis of course discussion forums afforded insight into the development of the student learning community by identifying disconnected students, patterns of student-to-student communication, and instructor positioning within the network. The results affirmed that pedagogically meaningful information can be extracted from LMS-generated student tracking data, and discusses how these findings are informing the development of a customizable dashboard-like reporting tool for educators that will extract and visualize real-time data on student engagement and the likelihood of success.

\section{B. LMS and Students Satisfaction with Learning}

Satisfaction on the part of the students plays an important role when teachers, their course program and the general quality of educational program are evaluated. Knowledge of the factors that influence satisfaction with e-learning initiatives can help improve such courses. Hopland and Nyhus [15], explored the relationship between satisfaction with learning environment and student effort, both in class and with homework assignments. The authors used data from a nationwide and compulsory survey to analyze the relationship between the learning environment and student effort. The survey covers all students attending the seventh (last year of primary school) and tenth (last year of lower secondary school) grades in Norwegian compulsory education. Results revealed that student satisfaction with teacher guidance, materials, and social environment plays an important role in stimulating effort both in class and with homework. Satisfaction with physical work conditions is of less importance but does stimulate in-class effort among the younger students. Heterogeneity across the genders for tenth graders is also observed. In particular, bullying and satisfaction with teacher guidance are more important determinants for males' than for females' effort. The study recommended that school managers should focus attention on improving not only the quality of teachers and teaching materials but also the social environment at the school in order to stimulate more student effort. The results of study contribute to the literature studying student effort and educational outcomes by providing information on how different school factors affect student effort.

In [16] authors, conducted a study, involving 1114 university students from southern Spain, to determine and analyze the main components influencing students' level of satisfaction with e-learning. The most relevant findings were that course design and contents, the facility for accessing and visualizing information on the teaching platform and the possibility of interaction were key aspects. The research also points to the importance of the professor as a motivating figure upon whom successful completion of a course largely relies. Jan [17] investigated the relationships between Academic Self-Efficacy (ASE), computer self-efficacy (CSE), prior experience, and satisfaction with online learning and explored how ASE, CSE, and satisfaction vary with age and gender. One hundred and three graduate students enrolled in purely online courses in January 2014 at a university in the midwestern United States participated in the survey. Scales with known reliability were used to measure ASE, CSE, and satisfaction. The study results showed a significant positive correlation among all the variables except CSE and satisfaction. Regression analysis showed ASE to be most predictive of satisfaction with online learning. Females had a higher mean ASE than males, and participants aged thirty-five years and above had a higher mean CSE than younger participants.

Many studies suggest factors that might influence online 
learning and assessment, but most have not been empirically tested. For example [18] reported on a survey data from 91 students to investigate what factors influence students' satisfaction with online assessment, and overall student satisfaction with the learning management system-Moodle. The survey questionnaire was sent anonymously to all students who took the online or hybrid course sections at a private Midwest university in summer 2013, as well as to all instructors who taught those courses. The result showed that overall student satisfaction with online learning is significantly affected by how the course is organized and how the content is sequenced, the ease with which students can complete assignments, and the use of the system to engage students with content.

In another study [19] explored graduate students end-of-term satisfaction with group learning, compared with traditional instructor-led instruction in EFL (English as a foreign language) classroom. Participants were 74 graduate students, including 33 males and 41 females from a normal university in southern China. The study was carried out with two classes by different teaching methodologies respectively, one was group-based $(\mathrm{n} / 35)$ with nine groups, and the other was an instructor-led class $(\mathrm{n} / 39)$. Students were assigned randomly to the two types of classes ahead of the formal lessons and taught by the same instructor during the period of an academic term. At the end of the term, a questionnaire survey was administered to all the students of the two classes to measure their satisfaction with English class learning. The results showed students with group-based instruction were more satisfied than those who took the course under the instructor-led format. Also, no significant differences existed between groups with respect to satisfaction. The results of the analysis were discussed and directions for further study were suggested. The significance of the present study lies in the fact that it was able to explore the difference in student satisfaction between group-learning and instructor-led settings in EFL class, and both instructor(s) and students should shift their focus "from what is being taught to what is being learned" in EFL classroom.

Bradford [20] explored the relationship between cognitive load and student satisfaction with learning online. A survey was conducted and 1401 students responded to an instrument that contained 24 items. Multiple analysis techniques found a positive, moderate, and significant $(\mathrm{p} \leq 0.01)$ correlation between cognitive load and satisfaction. Most importantly, the results found that approximately $25 \%$ of the variance in student satisfaction with learning online can be explained by cognitive load. New constructs emerged from a Principal Component Analysis suggest a refined view of student perspectives and potential improvement to guide instructional design. Further, a correlation, even a moderate one, has not previously been found between cognitive load and satisfaction. The significance of this finding presents new opportunities to study and improve online instruction. Several opportunities for future research are briefly discussed and guidelines for developing online course designs using interpretations of the emerged factors are made.

Arabian Gulf University is in the process of adopting and implementing innovative teaching and learning strategies based on interactive learning processes and delivering the learning contents via learning management systems such as Moodle and Blackboard with features that allow faculties and resources people from different departments to access, upload assignments, send quizzes, download content, and evaluate their students learning progress. Little research has been done to evaluate the impact of blending such an LMS system on technological programs graduate students' learning outcomes. The present study is mainly intended to assess the impact of a blended learning strategy based on Blackboard LMS on teaching a graduate course in research method taught for Technology Studies Graduate Programs at the Arabian Gulf University on some learning outcomes. Learning outcomes under investigation include academic developing research proposal performance skills and satisfaction with learning.

\section{Units Research Proposal Components}

Research is more than a set of skills; it is a way of thinking: examining critically the various aspects of day-to-day professional work; understanding and formulating guiding principles that govern a particular procedure; and developing and testing new theories that contribute to the advancement of your practice and profession. In [21] Kumar, proposed an eight steps model for conducating scientific research, these steps are: formulating a research problem, conceptualizing a research design, constructing research instruments for data collection, selecting a sample, writing a research proposal, collecting data and writing a research report.

On the other hand; a research proposal is a concept used to describe a document that is typically written by a scientist, academic or a graduate student to describe the ideas for an investigation on a certain topic. The research proposal outlines the proposed process from the beginning to the end and may be used to request financing for the project, certification for performing certain parts of research of the experiment, or as a required task before beginning a college dissertation. Writing a research proposal for post graduate degree is a very complex process involving a variety of elements. Consequently, analyzing the complex elements from introduction to data analysis sections in order to yield convinced research proposal writing through reviewing reputable journal articles is worth contributing.

Arifani [22] reported on a study aimed to improve students' ability in generating a research topic from reputable journal articles, developing thesis proposal draft, and writing a comprehensive thesis proposal. To satisfy this goal, a classroom action research administered at English Department University of Muhammadiyah Gresik Indonesia is adopted. Results revealed that the implementation of team-based discovery learning may improve students' ability in generating a research topic, developing research proposal draft and writing a comprehensive research proposal. Several suggestions are addressed by the author; first, although the syntax of the team based discovery learning is quite similar to the remaining strategies but will not work more optimally if it is not followed by relevant sets of guiding questions reflecting the detailed content of each reputable journal article in each meeting. Second, learning innovations activities through intensive writing practices and consultations should be taken into account to foster the steps of discovery learning in group discussion process. Finally, the results of commonalities of 
strategies may be used as a reference to enhance students ability in writing a comprehensive research proposal.

In this increasingly connected world where solving complex problems is not possible by solitary experts, educators and learners need opportunities to develop methods of thinking that allow them to engage with the dynamic and complex situations that arise in the world. The development of graduate attributes has been suggested as one way in which students can be prepared as active agents of social good. However, there are significant challenges with respect to developing these graduate attributes. Rowe [23] made use of a blogging platform to create a collaborative open online course using principles of authentic task design in order to develop graduate attributes in undergraduate physiotherapy students. The study used an interpretive, qualitative design that gathered data via focus group discussions. Transcripts were analyzed inductively in order to determine categories, which were then analyzed in relation to the graduate attributes of the institution in which the study took place. Student discussions suggested that they had developed at least some components of generic graduate attributes, including an approach to learning that was personal and internally motivated the ability to consider alternative points of view and acknowledge different perspectives, the confidence to challenge knowledge and authority, and skills as empathic communicators.

In [24] authors, conducted a critical review of research to date suggests a need to explore the development of graduate student research capacity from the standpoint of graduate students. Six members of an interdisciplinary graduate student colloquium at the Centre for Youth and Society (Victoria, Canada) offer their perspective. Their research involved four phases, each illustrating the processes that refined our understanding of the components that contributed to the development of our graduate student research capacity. First, they engaged in several round-table discussions and created a conceptual map depicting components that were meaningful in developing our research capacity. Second, they examined previous work on graduate student research capacity development and compared this data to the conceptual map. Third, they conducted a thematic analysis of secondary data of earlier graduated students with similar interdisciplinary training and involvement in the Centre. Finally, the data analysis was used to refine the conceptual map that may benefit educators and future graduate students. From the standpoint of students themselves, they discussed those components perceived as best contributing to the development of graduate student research capacity and highlight the importance of an interdisciplinary context and writing process.

A research proposal is a written plan of the study. It spells out in details what the researcher intends to do. It permits others to learn about the intended research and to offer suggestions for improving the study. The research proposal helps researchers to avoid unintended pitfalls and unknown problems. Developing a sound research proposal is one of the main goals of research method course at Arabian Gulf University. In general, there are four major sections of a research proposal are as follow [25]:

1) The problem to be investigated: this includes the statement of the problem or question, the research hypotheses and variables, and the definition of terms.

2) Background and review of related literature

3) Procedures: This includes a description of the sample, the instruments to be used, the research design, the procedures to be followed, an identification of threats to internal validity, and a description and a justification of the statistical procedures used.

4) Budget of Expected Costs

According to the Arabian Gulf University students`guide, a well-written research proposal should consistent of the flowing components: 1) proposal cover page, 2) research title, 3) research introduction/background, 4) the research problem, 5) the main question of the research, 6) sub-questions to be considered, 7) research hypotheses, 8) previous/related studies, 9) research goals, 10) research importance, 11) research design, 12) research terms and, 13) references.

\section{THE STUDY}

The current study was conducted in the Arabian Gulf University located in the Kingdom of Bahrain and funded by the Gulf Cooperation Council countries. The university looks forward to undertaking its role as a regional Gulf university in addressing the developmental issues of the Gulf Cooperation Council countries through its innovative and effective educational and research programs with relevance to Arabian Gulf regional issues and aspires to gain an eminent international reputation.

\section{A. Purpose of the Study}

The purpose of this study is to explore how blending Blackboard LMS at the Arabian Gulf University -College of Graduate Studies can improve the research method course learning outcomes. In more specific terms the study is going to show how the systematic approach to instructional development was utilized for developing learning material for course online delivery; and test the effect of using Blackboard as an educational delivery on the research methodology course learning outcomes related subjects' performance skills for writing research proposal as well as their satisfaction with course elements represented in (teaching strategy, course content and instructor of the course).

\section{B. Questions of the Study}

The main question addressed by this study is that: what are the impacts of utilizing the Blackboard Learning Management System at the Arabian Gulf University on the Graduate students who studying the Research Method Course at the College of Graduate Studies Technology Programs learning outcomes. In more specific the study is intended to answer the following questions:

1) What are the main components of the Blackboard research method course?

2) What is the impact of using the Blackboard LMS for teaching the Research Methods Course on technological sciences graduate students`skills for preparation of the master research proposal?

3) What is the impact of using the Blackboard LMS for teaching the Research Methods Course at the technological graduate programs on students' 
satisfaction with learning related to course teaching strategy, course content and course instructor?

\section{Hypothesis of the Study}

The study is sought to test the following two hypotheses:

1) Blending Blackboard LMS and face -to-face for teaching the Research Methods Course will en-hance technological sciences graduate students` skills for preparation of the master research pro-posal.

2) Blending Blackboard LMS and face-to-face - for teaching the Research Methods Course will lead technological graduate programs students' to a high level of satisfaction with learning related to course teaching strategy, course content and course instructor.

\section{The Importance of the Study}

The importance of the present study can be generated from the following considerations.

1) It's hoped that using Blackboard for teaching research methods course at the college of the graduate studies motivate others faculties at the Arabian Gulf University to use e-learning with their students for better learning outcomes.

2) It's hoped that using Blackboard as a learning management system for teaching the research method course will facilitate the learning interactions needed for successful learning.

3) It's hoped that the results of the study motivated Arabian Gulf university higher administration and curriculum developer to recommend blended learning utilization at the college of graduate studies.

\section{E. Limitation of the Study}

The treatment was limited to only one graduate course in research method required for the technological studies master and high diploma programs at the Arabian Gulf university, the generalization of results on similar courses, context and population possessed similar characteristics may be possible.

\section{F. Definitions of Terms}

Blackboard Learning System (LMS): is a course management system developed by Blackboard Inc. It is a Web-based server software which features convenient course management, customizable open architecture, and scalable design that allows for integration with student information systems and authentication protocols. In the present study Blackboard LMS refers to the Blackboard Learning Management System hosted by Blackboard ASP Solutions and used by the Arabian Gulf university science the academic year 2008/2009, with the main purposes of providing users with a platform for communication and sharing content to add online elements to courses traditionally delivered face-to-face and to develop completely online courses with little or no face-to-face meetings.

Distance education: Distance education refers to the method of education in which students can study in their own time, at the place of their choice (home, work or learning center), and without face-to-face contact with a teacher. In the present study, distance education refers to the situation in which Blackboard communication tools used for facilitating research method course candidates interactions with the needed learning resources (human and non-human).

Learning outcomes: Learning outcomes are the specific intentions of a program or module, written in specific terms. They describe what a student should know, understand, or be able to do at the end of that program or module. The learning outcomes of the research method course under investigation are achievement and satisfaction with learning.

Research Methods Course: TCM (0512) Research Methodology: is a graduate course designed to help students identify, define and formulate a research problem. It establishes the foundations of practical research methodologies, with emphasis on the planning and procedures of empirical research in interdisciplinary fields. It discusses via a series of well-structure tasks, the various aspects of research: problem selection, problem definition, research objectives, research strategies, methodology, data collection \& analysis, verification, evaluation, reporting and presentation of research results. Every student is expected to prepare a review paper on a subject related to his/her scientific background and prepares scientific presentations of a literature review of his/her proposed thesis, methodology, and /or fieldwork. Each student is expected to deliver two or more seminars. Satisfactory presentations and discussions in these seminars are prerequisites for the submission of the masters' thesis proposal.

Technological studies programs: Technical Studies: Programs currently can be taken as a master, or a master's level diploma. These programs are:

1) Desert and Arid Land Sciences which includes: Hydrology and groundwater resources management, Agricultural techniques and hydroponics, Environmental sciences and natural resources and Geographic information systems and remote sensing.

- Biotechnology which includes: Medical applications

- Agricultural applications

- Environmental applications

2) Technology Management Program

3) Environmental Management Program

Satisfaction with learning: Satisfaction can be defined as a happy or pleased feeling because of something that one did or something that happened to him/her. Satisfaction with learning in this study refers to happy and pleased feeling of the students because of their enjoyment and pleasure of method used for teaching and learning the course materials which integrate face -to-face presentation and e-learning via Blackboard LMS.

\section{METHODS AND PROCEDURES}

The aim of the present study was to explore using blackboard as a learning management system at higher education post graduate program. More specific the study was intended to assess the impacts of integration of the Blackboard LMS for teaching a research method graduate course for technology programs students studying at the college of graduate studies at the Arabian Gulf University learning outcomes. The learning outcomes under investigation included subjects' achievement in the course; subject's satisfaction with the learning experience and their 
skills related to writing a good research proposal.

\section{A. Population \& Sample}

The present study was conducted at the Arabian Gulf University - College of Graduate Studies during the second semesters of the academic years 2010/2011 \& 2011/2012. The population of the study composed of all students affiliated to the technical studies graduate programs.

The sample of the study was composed of all masters' students who registered for the research methodology: (TCM 0512). The sample of this study composed of 33 master's students who affiliated to Arabian Gulf University technology graduate programs who are studying the research method course during the second semester of the academic years 2010/2011 and 2012/2012 respectively. The controlled group size represents around $55.9 \%$ (19) who registered for the course during the academic year 2010/2011, while the experimental group represents $44.1 \%(15)$ of the sample size and studied the course during the academic years 2011/2012. Around $44 \%$ (15) are male and $56 \%$ (19) of the sample are female. The sample age range from 25 up to 42 years with age (mean $=30.38$ and $\mathrm{SD}=5.11$ ).

\section{B. Instrumentation and Validity of the Instruments}

The study used the following instruments:

Performance Checklist for assessing subjects` research proposal writing skills. The performance checklist is set up for evaluating subjects`acquired skills to develop a research proposal (13 items). This instrument aimed to verify acquiring the skills of research proposal preparing, and test how student apply these skills. The checklist was developed based on the various studies and educational research resources. And finally, a list of the main item included in a standardized research proposal was included; these included the flowing items that must be available in a research plan.

1) Proposal cover page.

2) Research Title.

3) Research Introduction.

4) Research problem.

5) The main Question of the Research.

6) Sub-questions to be considered.

7) Research Hypotheses.

8) Previous Studies / Related Research.

9) Research goals.

10) Research importance.

11) Research methods \& design.

12) Research terms.

13) References.

The study carried out a set of procedures to check the content validity; the instrument was reviewed by a group of experts and specialists and administrated on a sample of prospective graduate students in technological studies programs. Cronbach's alpha coefficient was also computed for any dimension of the performance list instruments as well as the scale as whole. Table I show the computed alpha coefficients values for the performance skills list dimension and the estimated value for the instrument as whole. The computed coefficients ranged from above average and high.

\section{The Satisfaction with learning Scale}

The satisfaction with learning scale (Table II) is one of the instruments employed for data collection in this study. It was constructed to measure the degree/level to which learners' were satisfied with learning experience by utilization of Blackboard LMS for teaching the research methodology course. The instrument was administrated after the experiment. The five-point Likert scale was used for measuring the responses. Responses to the survey items were coded from 1 to 5 .

TABLE I: COMPUTED ALPHA COEFFICIENTS VALUES FOR THE PERFORMANCE CHECKLIST

\begin{tabular}{|c|c|c|}
\hline List dimension & $\begin{array}{c}\text { \# of } \\
\text { elements }\end{array}$ & $\begin{array}{c}\text { Cronbach's } \\
\text { Alpha }\end{array}$ \\
\hline 1. Developing proposal cover page skill & 5 & $0.406 *$ \\
\hline 2. Selecting \& writing a research title skill. & 4 & $0.675 * *$ \\
\hline 3. Writing research introduction skill & 7 & $0.780 * * *$ \\
\hline 4. Stating the research problem skill & 5 & $0.836 * * *$ \\
\hline $\begin{array}{l}\text { 5. Stating the main question of the } \\
\text { research skill }\end{array}$ & 5 & $0.788 * * *$ \\
\hline 6. Sating sub-questions skill & 5 & $0.585 * *$ \\
\hline 7. Research Hypotheses. & 5 & $0.623 * *$ \\
\hline $\begin{array}{l}\text { 8. Reviewing previous \& related research } \\
\text { skill }\end{array}$ & 3 & $0.857 * * *$ \\
\hline 9. Stating the research goals skill & 3 & $0.603 * *$ \\
\hline 10. Writing research importance skill & 2 & $0.813 * * *$ \\
\hline 11. Developing research design skill & 8 & $0.592 * *$ \\
\hline 12. Defining research terms skill & 2 & $0.545 * *$ \\
\hline 13. Writing references skill & 2 & $0.342 *$ \\
\hline 14. Performance assessment lit & 56 & $0.758 * *$ \\
\hline
\end{tabular}

N.B. * Average ** above average *** high

In case the scale statement is positive, the numerical value 5 is assigned to strongly agree, 4 to disagree, 3 to undecided, 2 to agree and 1 to strongly disagree. In case the scale statement is negative, the order of scoring will be reversed. Moreover, it was written in the Arabic Language to be quick and easy for learners to rate the scale statements.

Developing the scale: As one goal of the present study was to assess technological graduate students`at the Arabian Gulf University; satisfaction with blended learning via Blackboard, the study reviewed many similar studies and developed the current yard stick. Many satisfaction with learning scale were found in these studies were not appropriate and couldn't measure what the researcher wanted to measure. Thus, the researchers benefited from other research studies that measure learners' level of satisfaction with the learning experience. With the help of these scales, a new scale version was constructed and developed according to three dimensions that were named as;

1) Satisfaction with the teaching strategy dimension; which assess the learners' level of satisfaction with the use of the proposed blended learning strategy for teaching the research methods course.

2) Satisfaction with the course content dimension; which assess the learners' level of satisfaction with the course content and course material.

3) Satisfaction with the course instructor/instructors, which intended to assess the learners' level of satisfaction with their instructors' and his support during delivering, administrating, guiding and evaluating the learning process. 
Regarding the scale validity, the first version of the scale was presented to a group of 5 experts in educational psychology, educational technology and teaching methods to provide suggestive feedback on the scale items. They were asked to review the scale statements according to the clarity and appropriateness of the language to the intended respondents; the extent to which each statement reflects the intended dimension and the experts provided some sound common-sense advice on designing the scale statements. Some of the items were rearranged and others were improved. After making the suggested improvements, items were distributed into the sub-dimension to form a 32-item satisfaction with learning scale.

TABLE II: DISTRIBUTION OF THE SATISFACTION WITH LEARNING STATEMENTS (COMPONENTS)

\begin{tabular}{cll}
\hline \hline No. & Dimensions & The statements \\
\hline 1 & $\begin{array}{l}\text { Teaching } \\
\text { Strategy. }\end{array}$ & $1,2,3,5,6,7,8,9,10,11 \& 12$ \\
\hline 2 & $\begin{array}{l}\text { Course } \\
\text { content. }\end{array}$ & $13,14,15,16,17,18,19,20,21 \& 22$. \\
\hline 3 & $\begin{array}{l}\text { Course } \\
\text { instructor. }\end{array}$ & $23,24,25,26,27,28,29,30,31 \& 32$ \\
\hline 4 & The scale & $1,2,3,4.5,6,7,8,9,10,11,12,13,14,15,16,17,18$ \\
& & $19,20,21,22,23,24,25,26,27,28,29,30,31,23$ \\
\hline \hline
\end{tabular}

\section{Item Analysis and Reliability of the Satisfaction with Learning Scale}

Regarding the scale reliability, a pilot study was conducted with random sample population at Arabian Gulf University Graduate College Technology Studies Programs students who study research method 2010/2011. Around 13 candidates were asked to rate their satisfaction with the research method course according to the scale items. Conducting a pilot study allowed the researchers to gather information about the modified scale items. Responses to the pilot scale were recorded, exported, and transferred to SPSS for in-depth analysis. After transferring scores to SPSS for making an in-depth analysis, the total value of Cronbach's alpha was .871. Then, the researchers measured the values of Cronbach's alpha for each dimension.

TABLE III: SATISFACTION WITH LEARNING INSTRUMENT RELIABILITY VALUES

\begin{tabular}{clc}
\hline \hline No. & Dimension & $\begin{array}{c}\text { Computed Cronbach's } \\
\text { alpha }\end{array}$ \\
\hline 1 & Teaching Strategy & .966 \\
\hline 2 & Course content & .780 \\
\hline 3 & Course instructor/instructors & .832 \\
\hline 4 & The whole scale & .934 \\
\hline \hline
\end{tabular}

From the presented results listed above, it is obvious that the total alpha value for all dimensions and scale's components is acceptable to confirm the suitability of the scale for measuring subjects`satisfaction with leaning.

\section{E. Procedures}

The current study has utalized a developmental research method for investigating the problems facing the technology graduate programs students who develop their masters' research proposals. This research approach emphasizes the study of learning as a result of designing unique instructional interventions [26]. It is also different from traditional research in instructional psychology, media comparison, and message design. However, well-conceived developmental research can offer a direct response to the many demands for research that is prescriptive and meets the pressing needs of practitioners [27].

The Blackboard Research Method Course: All the research method course material was developed installed and made available and accessible over the Arabian Gulf University Blackboard LMS via the asynchronous course communication tools. For the purpose of the present study, the "Research Methods" course was designed and developed as a blended learning course for them. In designing the blended course, formal and informal data gathered from the students who had already taken the course were examined. Then the instructors specified the desired outcomes of the course in terms of goals and objectives. At the end, the content, the practice items, and the assessment instruments were determined based on the course basic goal and objectives.

The course duration was 13 weeks. The course commenced with a 90-minute face to face lecture where the learners had the opportunity to meet each other and the instructor. In this f2f introductory sessions, participants were presented with the learning objectives of the course as well as the proposed learning strategy. The f2f sessions took place every second week. After the f2f lecture by the instructor, students were presented with problem solving activity to complete. A short summary lecture followed each activity. For the weeks when the students did not have f $2 \mathrm{f}$ meetings, they were expected to $\log$ onto the course individually from home, work or a University computing cluster, whichever was most convenient, and read that week's course material, download resources (such as lecture transcripts and journal papers), and follow instructions to complete tasks. Weekly quizzes and self-evaluation questions were given online. Also, they had to accomplish an online assignment due two days after the asynchronous online lecture. A second online assignment due at the end each week reinforced concepts dealt with in each lecture every week the course lasted. Students could communicate and interact with the instructor and with each other by e-mail or other forums. Students were expected to post their comments regularly in an asynchronous online forum and to comment on and generate ideas with other students while the instructor coordinated the procedure. Topics of discussions were related to the concepts introduced in the course's modules. All contributions were graded. Students' evaluation was based on their performance to the two weekly assignments and on an exam paper at the end of the semester and also to their participation in a weekly discussion concerning the thematic area of the week.

Using Hannifin-Peck Model for Developing Research Method Blackboard Course Material: The development of the proposed research method blackboard learning environment and the course material took place according to Hannafin Peck (1987) [28] instructional design model. Instructional design models help instructional designers to make sense of abstract learning theory and enable real-world application. The Hannafin Peck (1987) [28] design model is a 
three phase process. Fig. 1 blew shows the model phases and components.

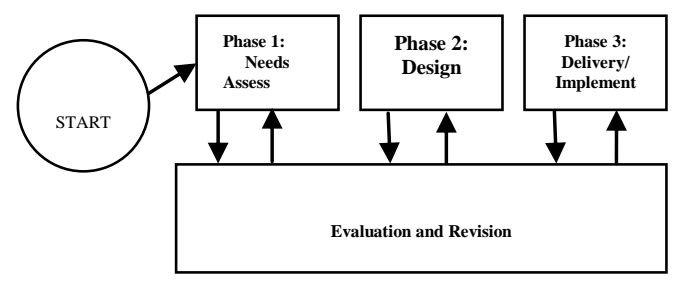

Fig. 1. Hannifin peck design and implementation of educational software model.

Phase I: Needs Assessment: Needs assessment phase consists of determining the program's objectives. It also requires an instructional designer to create reasonable goals for his project. The goal behind this work was to develop Blackboard learning Environment for teaching the research method course and assess its effectiveness in developing Arabian Gulf University Technology Program Masters` Students learning outcomes i.e. (writing masters' proposal performance skills and satisfaction with learning).

During this phase, the designer/system developer also needs to make an assessment, particularly on the characteristics of the target group. These include determining the following:

1) Who will use the software?

2) The user's prior knowledge?

3) What are the desired behaviors changes?

4) The objectives to be achieved?

5) What hardware and software required and so on?

The activities of this phase are to ensure that the design process has a guidance and direction that can be followed. In this phase, also the various elements, whether in terms of content, screen design, and system exploration will also be determined.

The proposed blackboard research method course was developed for technology programs masters` students. Candidates possess the required computer and information technology skills that help them to interact with the Blackboard LMS; also they possess the technical knowledge. The desired behavioural change was stated as learning objectives of the course units.

During this phase, the study also adopts and established instructional design standers for developing the course material as well as the proposed virtual learning environment. Analyze the target population (the students who study research method course at Arabian Gulf University technology graduate programs ...), identify the participates instructional need for Course in Research Methods and the Blackboard learning environment to support their research method instruction and analyze the available digital learning recourses and learning objects, learning management system, suggest the needed modification and proposed the newly designed content and learning resources.

Phase II: Design: In this phase, the overall view of the shape, structure, teaching approaches, learning theories, media, and technology types that will be involved is a matter to be investigated. That is why several employment measures have been implemented that determines how the performance-based approach to teaching and learning theories, and to determine the structure of the website produced flow chart.

During this phase, the research method course, as well as the accompanied Blackboard learning environment, was designed. The design activities include driving the course objectives (based on needs), analysis of IO and sequencing their instructional hierarchy, identifying the course content, elements and grouped in units, building the criterion-referenced test/tests (CRT) for each unit (pre and post tests), design learning experiences, learners grouping method, and learner instructions, and role of teacher/guide for each objective, choosing the elements of multimedia/learning objects for each objective, and making final selections, designing message and storyboards for the selected media/learning objects for production, designing the expert system navigation techniques, program instructional control, and learner interface, designing the instructional events [29] and elements of the learning process and building learning/teaching strategy, learner's interactions with the proposed research method course, external media, and facilities, and requirements depending on the environment of implementation.

Phase III: Development and Implementation: The final phase is development and implementation. During this phase, the program is put into work. Throughout the development phase, several things need to be taken into account apart from knowing that teaching method should be used in computer and e-learning delivery. This is because all the key elements that have been created in the previous phase will be translated into a more practical, with the help authoring system or programming language. Here the software that will be used in developing the website, as well as computer specifications to be used in developing the courseware will be mentioned.

In development and implementation phase, the students' workbooks, the instructor manual, the Blackboard learning environment, the learning activities, discussions, self-assessment questions, quizzes, and their feedback were developed. The e-content is written and graphics, audio, and photography are also produced and assembled. In the present study this phase composed of accessing/obtaining available learning objects, resources, and preparing facilities, modifying/ producing learning objects, multimedia elements using production tools and facilitates, digitization and storing multimedia elements and program authoring by using authoring system, set program strategy added external Production and media production, and facility preparation for use. Figure 2 shows the home page of the research method course.

Evaluation: However, this is not the only time for revision. As one can see in the figure above, evaluation and revision is a constant phenomenon. One difference between this model and many other models, like the Dick and Clark model, is that this one requires an evaluation following each phase. Furthermore, after the third phase of the model, there is a chance to revise your instructional software. This makes the model easy to use. Therefore, any designer or system developer with some knowledge can easily use the Hannifin Peck Model.

During the evaluation, the instructional designers (the authors) determine what success will look like and how it will 
be measured. In general, the evaluation consists of two phases: formative and summative. Formative evaluation is iterative and is done throughout the design and development processes. This occurs all throughout Hannifin and Peck ID model [27]. Summative evaluation consists of tests that are done after the learning materials are delivered (after complete studying each unit of the course). The results from these test help to inform the instructional designer and the stake holders on whether or not the learning accomplished its original goals outlined in the analysis phase.

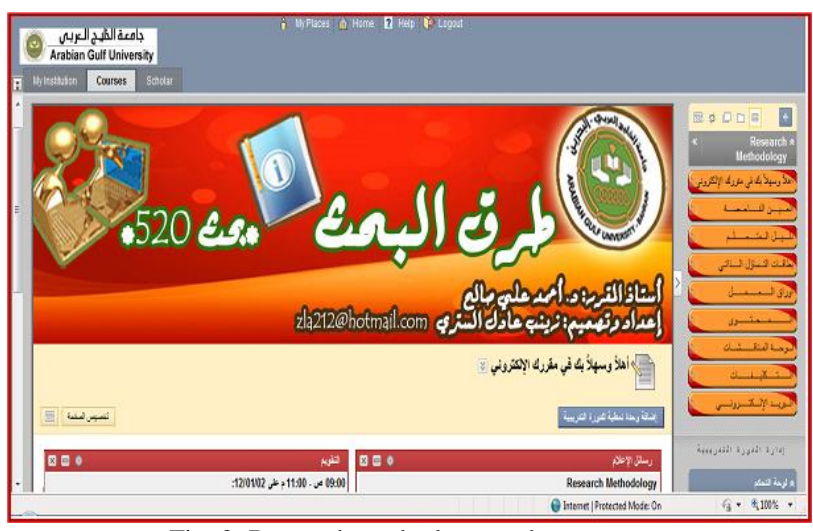

Fig. 2. Research method course homepage.

\section{F. Data Analysis}

Data analysis is a process for obtaining raw data and converting it into information useful for decision-making by users. In the present study, the statistical treatment of the collected data was carried out using the Statistical Package for the Social Sciences SPSS 18, according to the following statistical methods:

1) Descriptive statistics to compute subjects means, standard deviations, and percentages.

2) Cranach's alpha to measure internal consistency that is, how closely related a set of items are as a group. This test was used to compute instruments readability coefficients.

3) Independent sample T-Test and t-test's effect size (Eta) are used to compare experimental and control group different average values in the performance check list assessing research proposal writing skills.

4) The one sample T-Test is used to determine the impact of the proposed blackboard research method course on subjects satisfaction with learning compared to the normal mean of satisfaction of (3 out of 5) on a Likert 5 scale.

\section{RESUlTS AND DisCUSSION}

This section will present the results of the study based on the collected data and the proposed hypothesis of the study. Results related to study question and hypothesis will be clarified, the mechanism followed by authors as well as the statistical tests used will be highlighted. The section will be closed by discussing the study results based previous research and learning theories related to the topic of the paper.

\section{A. Results Related to Question 1}

Question1 addressing the following: what are the main components of the Blackboard Research Method Course?

Research method Blackboard course (EDR 0520) is 3 credit hours graduate course required course intended to be completed by all students who registered for the master degree in technological programs. The main goal of the course is to equipped the students with the basic knowledge and concepts related to scientific research, as well as developing skills required for conducting their master thesis or solve problems they faced in their field work.

The objective of designing special learning material to be uploaded on the Blackboard LMS was to integrate the strategies of distance learning material design so as to fit with all learning styles and motivate technical studies programs master`s students, and increase their desire to acquire the skills of research proposal preparations.

The content of the course is divided into 6 chapters and covering the following topics:

Chapter I: An introduction to research methods.

Chapter II: The research problem.

Chapter III: Variables and hypotheses.

Chapter IV: Research design.

Chapter V: Research sampling.

Chapter VI: Data collection methods

It is worth mentioning that one chapter of the course has been excluded because it is related to the topics taught within the Applied Statistics Course. To facilitate subjects learning using Blackboard LMS, the study installed the common Blackboard tools as shown in Table IV.

TABLE IV: COMMON BLACKBOARD TOOLS

\begin{tabular}{|c|c|}
\hline Tool & Description \\
\hline Quiz \& Exams & $\begin{array}{l}\text { Adaptable test and survey tool. Allows for various types } \\
\text { of questions (including matching, multiple choice, } \\
\text { short answer, essay, and more). Plenty of settings to } \\
\text { control delivery of exams. Great for self-practice. }\end{array}$ \\
\hline Glossary & $\begin{array}{l}\text { Key terms of the course can be easily added from a } \\
\text { publisher`s textbook website. This represents is a great } \\
\text { reference tool for students. }\end{array}$ \\
\hline Grade Book & $\begin{array}{l}\text { Manage course assignments and grades. Automatically } \\
\text { calculate participant point totals. Stop those repeated } \\
\text { calls from students needing to know how they are } \\
\text { doing. }\end{array}$ \\
\hline My Grades & $\begin{array}{l}\text { Student view of their graded activities and assignments. } \\
\text { Course instructors control what students see and what } \\
\text { feedback to be included. }\end{array}$ \\
\hline Learning Unit & $\begin{array}{l}\text { A way of organizing the content, learning units allow } \\
\text { instructors to create a sequential path through the } \\
\text { course materials, assignments, exams, etc. }\end{array}$ \\
\hline $\begin{array}{l}\text { Content Area } \\
\text { (Folders and } \\
\text { Items) }\end{array}$ & $\begin{array}{l}\text { Allow instructor to organize his content into } \\
\text { manageable "chunks" through the use of folders and } \\
\text { links. }\end{array}$ \\
\hline $\begin{array}{c}\text { Student } \\
\text { Homepages }\end{array}$ & $\begin{array}{l}\text { A way for students to introduce themselves to the } \\
\text { course instructor and to their classmates }\end{array}$ \\
\hline Class Roster & $\begin{array}{l}\text { Display all of the students enrolled in your Blackboard } \\
\text { course. Also used to view student homepages. }\end{array}$ \\
\hline Groups & $\begin{array}{l}\text { Break up your class into smaller groups. Provides } \\
\text { private areas and tools for students to work together. }\end{array}$ \\
\hline
\end{tabular}

\section{B. Results Related to Question 2}

Question 2 stated as follows: What is the effect of blending the Blackboard LMS for teaching the Research Methods Course on technological sciences graduate students`skills for preparation of the research proposal compared to the 
traditional teaching method?

To answer the second question of the study, the following hypothesis: " Blending Blackboard LMS for teaching research method course will affect technological programs masters students` skills for preparation of the research proposal compared with the traditional teaching method".

Subjects`skills for preparation of the research proposal were assisted by using a performance checklist developed specially for the purpose of the study. The items of the performance list are: Research Cover Page Preparation Skill, Identifying and formulating a research title Skill, Writing Research Introduction Skill, Identifying and Formulating
Research Problem Skill, Writing Main Research Question Skill, Writing Research sub-Questions Skill, Writing Research Hypotheses Skill, Choosing and Reviewing Previous and Related Studies Skill, Writing Research Objectives Skill, Writing the Importance of Research Skill, Research Design Skill, Definition of Research Terms Skill, and References Writing Skill.

The hypothesis was tested via independent samples T-Test, comparing the experimental group average with the control group average on performance skills checklist. Table V, show the independent sample T-Test $(\mathrm{p}=0.05)$ and the effect size (Eta) results.

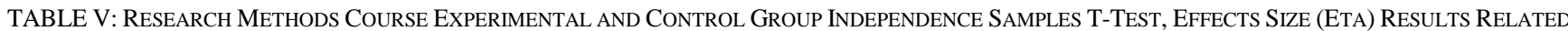
TO PREPARATION OF RESEARCH PROPOSAL SKILLS

\begin{tabular}{|c|c|c|c|c|c|c|c|}
\hline \multirow{2}{*}{ The skill } & \multicolumn{2}{|c|}{ Control Group } & \multicolumn{2}{|c|}{ "Excremental Group } & \multirow{2}{*}{$\mathrm{t}$} & \multirow{2}{*}{ Observed t } & \multirow{2}{*}{$\begin{array}{l}\text { Effect Size } \\
\quad \text { Eta }\end{array}$} \\
\hline & $\mathrm{M}$ & $\mathrm{SD}$ & $\mathrm{M}$ & SD & & & \\
\hline Developing cover page & 32.44 & 5.48 & 38.57 & 10.18 & 2.014 & 0.058 & - \\
\hline Writing a research title & 26.88 & 6.00 & 32.29 & 3.34 & 3.101 & 0.005 & 0.901 \\
\hline $\begin{array}{l}\text { Writing research } \\
\text { introduction }\end{array}$ & 43.38 & 10.73 & 51.93 & 5.36 & 2.813 & 0.010 & 0.797 \\
\hline $\begin{array}{l}\text { Stating a research } \\
\text { problem }\end{array}$ & 43.19 & 6.53 & 47.43 & 5.59 & 1.896 & 0.068 & - \\
\hline $\begin{array}{l}\text { Stating the main } \\
\text { question of the research }\end{array}$ & 21.00 & 5.34 & 36.43 & 9.46 & 5.396 & 0.000 & 2.888 \\
\hline Stating sub-questions & 11.75 & 6.11 & 27.43 & 14.97 & 3.662 & 0.002 & 2.568 \\
\hline $\begin{array}{l}\text { Writing research } \\
\text { hypotheses. }\end{array}$ & 10.13 & 4.83 & 22.07 & 13.69 & 3.102 & 0.007 & 2.473 \\
\hline $\begin{array}{l}\text { Reviewing previous \& } \\
\text { related research }\end{array}$ & 19.00 & 6.09 & 23.36 & 2.13 & 2.681 & 0.015 & 0.716 \\
\hline Stating research goals & 18.06 & 6.12 & 21.57 & 4.16 & 1.858 & 0.074 & - \\
\hline $\begin{array}{l}\text { Writing research } \\
\text { importance }\end{array}$ & 13.44 & 3.08 & 14.43 & 3.69 & 0.802 & 0.429 & - \\
\hline $\begin{array}{l}\text { Developing research } \\
\text { design }\end{array}$ & 32.75 & 11.26 & 49.14 & 11.95 & 3.866 & 0.001 & 1.455 \\
\hline Defining research terms & 3.75 & 2.910 & 9.29 & 7.436 & 2.616 & 0.018 & 1.903 \\
\hline Writing references & 15.38 & 2.419 & 17.71 & 1.069 & 3.498 & 0.002 & 0.967 \\
\hline $\begin{array}{l}\text { Performance assessment } \\
\text { list }\end{array}$ & 291.13 & 53.936 & 391.64 & 56.275 & 4.991 & 0.000 & 1.864 \\
\hline
\end{tabular}

The results showed in (Table V) above, indicate that the means of the experimental group tended to be higher than the means of the control group in all the masters' proposal preparation sub-skills. All computed values (observed) of $t$ are statistically significant at $(p \leq 0.05)$; expect 4 sub-skills that showed no significant differences in experiment and control groups means. These are:

1) Developing Cover Page Skill, for the experimental group $(\mathrm{M}=38.57, \quad \mathrm{SD}=10.18)$, the control group $(\mathrm{M}=32.44, \mathrm{SD}=5.48),(\mathrm{p}=2.01)$ not significant at 0.05 level.

2) Stating a Research Problem Skill, for the experimental group $(\mathrm{M}=47.43, \mathrm{SD}=5.59)$, the control group $(\mathrm{M}=43 \ldots 19, \mathrm{SD}=6.53),(\mathrm{p}=1.896)$ not significant at 0.05 level.

3) Stating Research Goals Skill, for the experimental group $(\mathrm{M}=21.57, \quad \mathrm{SD}=4.15)$, the control group $(\mathrm{M}=18.06, \mathrm{SD}=6.12),(\mathrm{p}=1.858)$ not significant at 0.05 level.

4) Writing Research Importance Skill, for the experimental group $(\mathrm{M}=14.43, \mathrm{SD}=3.96)$, the control group $(\mathrm{M}=313.44, \mathrm{SD}=3.08),(\mathrm{p}=0.802)$ not significant at 0.05 level.

In general, the sum of performance skills assessment list for the experimental group is higher than the sum of the control group performance skills; for the experimental group $(\mathrm{M}=391.64, \quad \mathrm{SD}=56.28)$, and for the control group $(\mathrm{M}=291.13, \mathrm{SD}=53.94)$; computed value of $(\mathrm{t}=4.99)$ which is statistically significant at the level of significance 0.05 .

\section{Results Related to Question 3}

Question 3 stated as follow: what is the impact of using the Blackboard LMS for teaching the Research Methods Course at the technological graduate programs on students' satisfaction with learning related to course teaching strategy, course content and course instructor?

To answer the $3^{\text {rd }}$ question the study, the authors test the study second hypothesis satiating: blending Blackboard LMS and face-to-face - for teaching the Research Methods Course will lead technological graduate programs students' to a high level of satisfaction with learning related to course teaching strategy, course content and course instructor.

The satisfaction with learning instrument was administrated at the end of the study and was answered by 13 candidates (experimental group only). Table 6 presents descriptive statistics results.

From Table VI; all satisfaction with learning components scored means ranged from above average to very high. The course instructor component scored the highest mean of 
satisfaction i.e. $(\mathrm{M}=4.67, \mathrm{SD}=.40)$, then came the satisfaction with the course content $(\mathrm{M}=3.99, \mathrm{SD}=.54)$ and the teaching strategy $(\mathrm{M}=3.97, \mathrm{SD}=.96)$. The total satisfaction with learning instrument scored an average mean of $(\mathrm{M}=4.20)$ and standard deviation of $(\mathrm{SD}=.54)$ which judged as a high level of satisfaction.

TABLE VI: SATISFACTION WITH LEARNING DESCRIPTIVE STATISTICS RESULTS

\begin{tabular}{|l|l|l|l|l|l|}
\hline Satisfaction component & $\mathrm{N}$ & Min. & Max. & Mean & Judge \\
\hline Teaching Strategy & 13 & 1.75 & 5.00 & 3.97 & .96 \\
\hline Course Content & 13 & 3.10 & 4.80 & 3.99 & .54 \\
\hline Course Interlocutor & 13 & 3.90 & 5.00 & 4.67 & .40 \\
\hline Whole Instrument 1 & 13 & 2.94 & 4.88 & 4.19 & above average \\
\hline
\end{tabular}

TABLE VII: PRESENTS ONE SAMPLE BLACKBOARD COURSE SATISFACTION WITH LEARNING T-TEST RESULTS

\begin{tabular}{|c|c|c|c|c|c|c|}
\hline \multirow{3}{*}{$\begin{array}{l}\text { Satisfaction } \\
\text { component }\end{array}$} & \multicolumn{6}{|c|}{ Test Value $=\mathbf{3}$} \\
\hline & \multirow[t]{2}{*}{$\mathrm{t}$} & \multirow[t]{2}{*}{ df } & \multirow[t]{2}{*}{ Sig.-2 (tailed) } & \multirow[t]{2}{*}{$\begin{array}{l}\text { Mean } \\
\text { Differ. }\end{array}$} & \multicolumn{2}{|c|}{$\begin{array}{l}95 \% \text { Confidence } \\
\text { Interval of the } \\
\text { Difference }\end{array}$} \\
\hline & & & & & Lower & Upper \\
\hline Teaching Strategy & 3.642 & 12 & .003 & .96795 & .3888 & 1.5471 \\
\hline Course Content & 6.635 & 12 & .000 & .99231 & .6665 & 1.3182 \\
\hline Course instructor & 14.939 & 12 & .000 & 1.66923 & 1.4258 & 1.9127 \\
\hline The Instrument & 8.039 & 12 & .000 & 1.19471 & .8709 & 1.5185 \\
\hline
\end{tabular}

To test where satisfaction components were significant or not, one sample t-test was conducted comparing these means of satisfaction components to the normal mean of satisfaction $\mathrm{m}=3$, Table VII).

One sample t-test results (Table VII) indicated that all Blackboard course satisfaction with learning components (the teaching strategy, the course content, the module instructor as well as the whole course) means compared to the normal satisfaction level ( $m=3$ out of 5 ) was statistically different, at the .05 level of significance, from the normal value of 3 . Results showed that the Arabian Gulf University technology programs masters' students are highly satisfied with the integration of the Blackboard LMS and face-to-face for teaching research method course i.e. (all means of satisfaction components represented in the teaching strategy, the course content and the course instructor, as well as the whole course, scored an average mean of satisfaction greater that the normal mean of satisfaction of $\mathrm{M}=3$ ).

\section{Discussion}

The proposed blended learning strategy based on Blackboard used in the current study significantly affected technological programs graduate students performance skills for research proposal preparation as well as their satisfaction with learning using Blackboard LMS. Possible explanations for the significant results related to the present study are:

Blackboard LMS tools facilitate interactions between the students, the course instructor and the learning contents. This explained the fact that field of experience and helps the learners to navigate multi-resources of knowledge and make use of their class mate and their course instructor feedback. These results are similar to Firat [11] and Hussein [4] who found that using LMSs like Blackboard increase academic achievement only when LMSs included such features as effectiveness, interaction, reinforcement, attractive design, social media support, and accessibility.

The learning material was designed in a manner that facilitates an easy learning process and is suitable for different learning styles. Good learning materials are important because they can significantly increase student achievement and support student satisfaction with learning. These results are comparable with [16] and [6] who found that overall student satisfaction with online learning is significantly affected by how the course is organized and how the content is sequenced, the ease with which students can complete assignments, and the use of the system to engage students with content.

Doing the learning activities helped the students to practice the skills and master the learning experience. The use of Blackboard LMS helped the students to put into practice the learning experience. The result is consistent with [12] where integration of LMS such as Moodle is found to give the students an additional platform to practice, collaborate and discuss speech writing. Out of many teaching-learning facilities available on LMS, the student chose online forum as a tool for giving additional practice in speech writing.

Experimental group candidates taught by the use of Blackboard LMS expressed a high level of satisfaction with the proposed blended learning strategy used for teaching the course. This result is similar to [19] who indicated that students with group-based instruction were more satisfied than those who took the course under the instructor-led method.

The communication between the course instructor/ instructors, students themselves, and the continuous feedback positively affect subjects`motivation towards learning and help the students in mastering the course objectives and developed the skills required for writing a research proposal.

\section{CONCLUSION AND RECOMMENDATION}

In concussion, the results of this study have several important implications for blended learning course design and quality improvement in higher education in shifting post graduate classroom context from a traditional teaching approach to blended learning context in which the candidate accesses learning material and do learning activities over the Internet. Research method and other courses taught for technological programs graduate students at the Arabian Gulf 
University content as well as teaching strategies can be enhanced to a degree that lead to a high level of satisfaction with learning. Arabian Gulf University staff members need to be trained on how to develop online courses and administrate their students learning via Blackboard LMS. Thus, Arabian Gulf University future strategy should focus on online course development and training faculty in developing more effective approaches for the graduate course. A good balance between content development, teaching strategies, and instructor possessed blended learning competencies will lead to high quality of teaching and learning outcomes.

Based on the results the study recommends the following:

1) Train AGU faculties in integrating Blackboard LMS in their teaching, and develop their instructional design competencies related to blended learning course development.

2) Encourage Arabian Gulf University faculties to train their students on how to use active learning strategies based on Blackboard LMS, and demonstrate its usefulness in learning and training.

3) There is a need to review the Arabian Gulf University graduate programs curriculum and update the research methods course topics and the teaching strategy and give the students more practice so as to link the theory with its field implication.

4) Applying the current study on a large randomized sample for expanding population generalization.

5) Applying the current study, on others courses for expanding ecological generalization.

6) Conduct a study to develop a tool for assessing the skills of preparing a research plan in all research methods courses taught at the Arabian Gulf University.

7) The study recommended that Arabian Gulf University should customize LMS like Blackboards' software to the needs of the graduate college staff to their courses in English and in Arabic to enhance the accessibility and usability of such software and accelerate the learning outcomes.

\section{ACKNOWLEDGMENT}

The authors would like to thank the technological programs masters`students who participated in this study, department of direst and land sciences for hosting the experiment, distance learning department for technical facilitation the Blackboard LMS and the review of the online-learning material. Special thanks go the Arabian Gulf University for funding the participation in the 6th 2017 International Conference on Education and Information Technology held at Cambridge University- UK.

\section{REFERENCES}

[1] H. P. Nii, "The blackboard model of problem solving and the evolution of blackboard architectures. Association for the advancement of artificial intelligence (www.aaai.org)," AI Magazine, vol. 7, no. 2, pp 39-53, Summer 1986.

[2] N. Umunnakwe and Q. Sello, "Effective utilization of ICT in English language learning - The case of University of Botswana undergraduates," Universal Journal of Educational Research, vol. 4, no. 6, pp. 1340-1350, 2016.

[3] U. T. Alturki, A. Aldraiweesh, and Kinshuck, "Evaluating the usability and accessibility of LMS "blackboard" at King Saud University,"
Contemporary Issues in Education Research, vol. 9, no. 1, pp.33-44, First Quarter 2016.

[4] Mohammad H. H. El-ghamry, "The effect of blackboard collaborate-based instruction on pre-service teachers' achievement in the EFL teaching methods course at faculties of education for girls," English Language Teaching, vol. 9, no. 3, pp. 49-67, February 2016.

[5] L. Yu-Je, "A study of the influence of instructional innovation on learning satisfaction and study achievement," The Journal of Human Resource and Adult Learning, vol. 4, no. 2, pp. 43-54, December 2008.

[6] C. Yi- Ju and C. Po-Chung, "Effects of online interaction on adult students' satisfaction and learning," The Journal of Human Resource and Adult Learning, vol. 3, no. 2, pp. 78-89, 2007.

[7] G. Salmon, E-tivities: The Key to Active Online Learning, London: Kogan Page, 2002, ch. 2, pp. 10-36.

[8] K.-S. Hong, "Relationships between students' and instructional variables with satisfaction and learning from a web-based course," Internet and Higher Education, pp. 267-281, May 2002.

[9] S. D. Johnson, S. R. Aragon, and N. Shaik, "Comparative analysis of learner satisfaction and learning outcomes in online and face-to-face learning," Environments. Journal of Interactive Learning Research, vol. 11 , no. 1 , pp. $29-49,2000$.

[10] D. Williams and A. Whiting, "Exploring the relationship between student engagement, twitter, and a learning management system: A study of undergraduate marketing students," International Journal of Teaching and Learning in Higher Education, vol. 28, no. 3, pp. 302-313, 2016.

[11] M. Firat, "Determining the effects of LMS learning behaviors on academic achievement in a learning analytic perspective," Journal of Information Technology Education: Research, vol. 15, pp. 75-87, 2016.

[12] P. Lata and S. Luhach, "An exploratory investigation of online forum mediated collaborative learning of speech writing: A case study," Journal of English Language Teaching, vol. 4, no. 1, pp. 18-28, Jan-Mar 2014

[13] A. Lai and P. Savage, "Learning management systems and principles of good teaching: Instructor and student perspectives," Canadian Journal of Learning and Technology, vol. 39, no. 3, pp. 1-21, Summer 2013.

[14] L. P. Macfadyen and S. Dawson, "Mining LMS data to develop an "early warning system" for educators: A proof of concept," Computers \& Education, vol. 54, no. 2, pp. 588-599, Feb. 2010.

[15] A. O. Hopland and O. H. Nyhus, "Learning environment and student effort," International Journal of Educational Management, vol. 30, no. 2, pp. 271-286, 2016.

[16] C. Dziuban, P. Moskal, J. Thompson, L. Kramer, G. DeCantis, and A. Hermsdorfer, "Student satisfaction with online learning: Is it a psychological contract? Online Learning, vol. 19, no. 2, pp. 1-15, March 2015.

[17] S. K. Jan, "The relationships between academic self-efficacy, computer self-efficacy, prior experience, and satisfaction with online learning," American Journal of Distance Education. [Online]. 29(1). pp.30-40. Mar. 2015.

[18] X. Hongjiang, S. Mahenthiran, and K. Smith, "Effective use of a learning management system to influence on-line learning," presented at the International Conference on Cognition and Exploratory Learning in Digital Age (CELDA) (11 $\left.{ }^{\text {th }}\right)$, Porto, Portugal, Oct. 25-27, 2014.

[19] W. Li and S. Mu, "Graduate student end-of-term satisfaction with group-based learning in EFL classroom," English Language Teaching, vol. 7 , no. 8, pp. 62-67, 2014.

[20] G. R. Bradford, "A relationship study of student satisfaction with learning online and cognitive load: Initial results," Internet and Higher Education, vol. 14, no. 4, pp. 217-226, Sep. 2011.

[21] R. Kumar, Research Methodology: A Step-by-Step Guide for Beginners, SAGE Publication, London: UK. 1999, ch. 2, pp. 35-45.

[22] Y. Arifani, "The implementation of team-based discovery learning to improve students' ability in writing research proposal," International Education Studies, vol. 9, no. 2, pp. 111-119, Feb 2016.

[23] M. Rowe, "Developing graduate attributes in an open online course," British Journal of Educational Technology, vol, 47, no. 5, pp. 873-882, Sep. 2016.

[24] M. M. Ryan, R. S. Yeung, M. Bass, M. Kapil, S. Slater, and K. Creedon, "Developing research capacity among graduate students in an interdisciplinary environment," Higher Education Research and Development, vol. 31, no. 4, pp. 557-569, April 2012.

[25] J. R. Fraenkel and N. E. Wallen, How to Design and Evaluate Research in Education, McGraw-Hill Publishing Company, Boston: USA, 2010, ch. 25, pp. 616-642. 
[26] The Design-Based Research Collective. (January/February 2003). Design-based research: An emerging paradigm for educational inquiry. Educational Researcher. [Online]. 32(1), pp. 5-8. Available: http://www. designbasedresearch.org/reppubs/DBRC2003.pdf

[27] R. C. Richey, "Research on instructional development," Educational Technology Research and Development, vol.45, no. 3, pp. 91-100, September 1997.

[28] M. Hannafin and K. Peck, The Design, Development, and Evaluation of Instructional Software, $1^{\text {st }}$ ed. Macmillan Publishing, New York. 1988, ch 5, pp. 58-78.

[29] R. M. Gagne, The Conditions of Learning and Theory of Instruction (4th ed.). New York: Holt, Rinehart \& Winston, 1985.

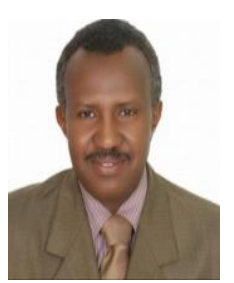

Alajab Mohammed Alajab Ismail is an associate professor in instructional technology \& distance learning, Arabian Gulf University, TDTP. Dr. Alajab received the B. Sc. \& education (honors) in physics (1989), the M.Ed. (1994) and the PhD. (2002) in educational technology from Khartoum University in Sudan (2002). In 2012, he received a second $\mathrm{PhD}$ in computer science majored in ICT from Rise University, Online School of Computer Science (USA).

Dr. Alajab has worked for several higher education institutions and teachers` colleges; Faculty of Education University of Khartoum (1990-2007), Sudan Open University (2005-2007), Albaha Teachers` College-Saudi Arabia (1998-2002), Faculty of Education-Sultan Quinoas
University. He has taught at the under graduate level for over 12 years, and graduate level for over 15 years.

In 2005, he joined the AGU and rising to an associate professor rank by 2011. He wrote the material for the King Hammed (the King of Bahrain) e-learning academic chair. He served as a Vice Dean for Scientific \& Academic Affairs at the Faculty of Education University of Khartoum, director of the DTTP at the AGU, supervised and examined many master's and doctorate thesis in educational technology, distance education, and science education. In addition he published and reviewed journals articles in his field.

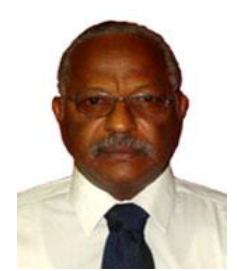

Ahmed Ali Salih is graduated from University of Khartoum in 1975 majoring in soil Science and obtained the $\mathrm{PhD}$ from University of California, Riverside, USA in 1984. He worked for the Agricultural Research Corporation of Sudan and later joined the Sudan Academy of Science. He worked with FAO to formulate the National Agricultural and Water Policies. He is promoted to professorship in 1998 and joined AGU since 2008. Currently he is doing research in the following fields: salinity and draught tolerance of crops, crop water requirement, hydroponic systems and reclamation of degraded lands. He published many articles in international refereed journals and is supervising $\mathrm{PhD}$ and MSc students. 